\title{
Evaluation of the Contamination by Herbicides in Olive Groves
}

\author{
Antonio Ruiz-Medina and Eulogio J. Llorent-Martínez \\ University of Jaén \\ Spain
}

\section{Introduction}

The application of phytosanitary products on the ground is one of the main employed procedures to solve the problems of plagues and diseases in olive groves. As a result, there is an increasing unease related to the possible presence of residues from these products in the olive-derived foods. Recent studies have shown that these residues can be found in olives and olive oil (mainly insecticides and fungicides) due to the lipophillic nature of the used plaguicides. This is also the effect that has been observed with the introduction of herbicides in this cultive. However, the detected levels of all these phytosanitary products are usually below the maximum residue limits (MRLs) established.

Herbicides are used by olive farmers to weed olive plantations with two essential goals: (1) eliminate the competition for water resources between olive trees and weeds, especially in particular moments of the productive cycle; and (2) keep the soil clean around the olive tree (in that way, the harvest of the olive fruits is easier if they fall off the tree after maturation is over). The main herbicides commonly used in olive groves are triazines (simazine, atrazine, trietazine, terbuthylazine and terbutryn), phenylurea diuron and phenylether oxifluorphen. All of them are directly applied on the ground of the plantation and nowadays widely used in intensified-traditional and modern-intensive olive groves. Herbicide residues remain highly concentrated in the top $5-15 \mathrm{~cm}$ of soil, even after several months. This fact presents two main consequences. First, herbicide residues are washed into streams, rivers and reservoirs with the soil that is eroded in heavy rains, polluting surface waters. Second, when harvesting is done using various devices to shake the olives off the trees without extending nets under the tree, olives come in contact with the herbicides present in the soil. This constitutes a risk of these herbicides being incorporated in olives and, consequently, olive oil.

Olive oil is a very important commodity in the Mediterranean basin. This product has a great importance in the sustainable economy of important regions from the main olive oil producers in the world: Spain, Italy and Greece. Due to the facts that virgin olive oil production has increased in recent years and that it is being exported to different countries, exhaustive quality controls are required. Different regulations regarding MRLs in olives and olive oil have been established by the European Union and the Codex Alimentarius of the Food and Agriculture Organization of the United Nations. In addition, new regulations will be established in following years with MRLs of $10 \mu \mathrm{g} / \mathrm{kg}$. 
There are alternative methods available for the analysis of herbicides in different kinds of samples. However, the common methods of analysis for their determination are Gas Chromatography (GC) and Liquid Chromatography (LC). GC is usually the chosen technique due to the high separation efficiency and compatibility with a wide range of detection techniques. Our research group has performed thorough investigation over the analysis of herbicides in soils, olive fruits and virgin olive oils. In particular, we have developed different GC analytical methods with mass spectrometric detection for the analysis of all the main herbicides used in olive groves. In this way, sensitive and reliable procedures can be implemented for the quality control of olives and olive oils in the industry. These methodologies, together with the obtained results over real samples from Spain, will be commented in this chapter.

\section{Composition and properties of olive oil. Classification}

Olive oil is composed mainly of triglycerides (98-99\% of the olive oil) and contains small quantities of free fatty acids (FFA), being the proportion of FFA variable and related to the degree of hydrolysis of the triglycerides. The composition of fatty acids in the oil depends on the variety of the olive tree, climatic conditions and geographical localization of the grove. Both the International Olive Council (IOC) and the Codex Alimentarius Comission have established maximum and minimum percentages for each fatty acid in the composition of the olive and pomace-olive oils. Olive oil is basically composed of mono-insaturated fatty acids. Regarding the degree of insaturation, fatty acids composition is as follows: $72 \%$ mono-insaturated, $14 \%$ poli-insaturated and $14 \%$ saturated.

There are also minor components in olive oil, which are specific markers of its physicochemical authenticity and they also add unique sensory and biological characteristics:

- Squalene is the major olive oil terpenoid hydrocarbon (300-700 $\left.\mathrm{mg} \mathrm{L}^{-1}\right)$, whereas $\beta$ carotene, biological precursor of vitamin A, is found in small quantities ( $\left.\mathrm{mg} \mathrm{L}^{-1}\right)$.

- Triterpenoids alcohols (24-methylenecycloartanol, cycloartenol, $\alpha$-amirine and $\beta$ amirine) are especially important from the biological point of view. Eritrodiol is also important from the analytical perspective, because it can be used to detect the presence of pomace-olive oil.

- Sterols can be used to construct a fingerprint in order to authenticate the olive oil, specifically using the $\beta$-sitosterol content, which represents around $93 \%$ of the total content of sterols.

- Tocopherols, especially a-tocopherol or vitamin E (150-300 mg L-1) are important antioxidants.

- Phenolic compounds, some of them contribute to the characteristic flavor of olive oil, increase the antioxidant properties of the oil.

- Approximately one hundred aromatic compounds are also present, being the exact chemical composition dependent on the variety, climatic conditions and quality of the oil.

Virgin olive oil is the most digestible of the edible fats and it helps to assimilate vitamins A, D and $\mathrm{K}$. It contains essential acids that cannot be produced by our own bodies and slows down the aging process. It also helps bile, liver and intestinal functions. It is noteworthy that olive oil has a beneficial effect in the dietary treatment of diabetes. In addition, it helps to control blood 
pressure and increases the bone mass. Moreover, olive oil has a favorable effect on the development of the central nervous and vascular systems, in brain development as well as normal child development (Cicerale et al., 2010; El \& Karakaya, 2009).

The human body easily absorbs olive oil. This means that the body absorbs the good ingredients such as vitamin $\mathrm{E}$ and phenols, which have anti-oxidizing properties and prevent the oxidization of fatty tissue, therefore helping to delay the aging process. In addition, it is not only easy to digest but it also helps the digestion of other fatty substances because it helps the secretions of the peptic system and stimulates the pancreatic enzyme lipase. On the other hand, olive oil consumption has a very positive effect on blood cholesterol (limits the oxidizing of bad cholesterol because it is rich in anti-oxidizing agents, as it was indicated before).

Olive oil, as any fatty substance, deteriorates during the frying process, especially if it is used over and over and if the frying temperature is very high. High temperature destroys the good ingredients of any oil while it creates harmful agents for the liver, the arteries and the heart. However, it is important to take into consideration that these harmful agents are less likely to be created in olive oil than in all other known vegetable oils because of the different composition. Olive oil contains a high percentage of oleic acid, which is much more resistant to oxidization than polyunsaturated acids (found in large amounts in seed oils). As a result, olive oil is the most stable fat and it stands up well to high frying temperatures.

Taking into account all the procedure in order to obtain the oil, edible olive oil is marketed in accordance with the following designations and definitions (International Olive Council, 2010):

1. Virgin olive oil: it is the oil obtained from the fruit of the olive tree solely by mechanical or other physical means under conditions, particularly thermal conditions, that do not lead to alterations in the oil, and which have not undergone any treatment other than washing, decantation, centrifugation and filtration. The virgin olive oils that are fit for consumption are extra virgin olive oil and virgin olive oil, presenting a free acidity, expressed as oleic acid, of not more than 0.8 and 2 grams per 100 grams, respectively. They also have to fulfil different quality criteria that, according to the IOC, include good organoleptic characteristics (taste and aroma) and low peroxide value.

2. Olive oil: it is the oil consisting of a blend (approximately 80:20 v:v) of refined olive oil and virgin olive oils fit for consumption as they are. It has a free acidity, expressed as oleic acid, of not more than 1 gram per 100 grams and its other characteristics correspond to those fixed for this category in this standard.

3. Olive pomace oil: it is the oil obtained by treating olive pomace with solvents or other physical treatments, to the exclusion of oils obtained by re-esterification processes and of any mixture with oils of other kinds. The marketed olive pomace oil is the oil comprising the blend (approximately 80:20 v:v) of refined olive-pomace oil and virgin olive oils fit for consumption as they are. It has a free acidity of not more than 1 gram per 100 grams.

Chemical processing may improve high acidity olive oil and make it edible; however, it takes away some extremely valuable ingredients such as vitamins and phenols. As a result, processed olive oil (refined) lacks the desirable properties and characteristics that can be found in abundance in (extra) virgin olive oil. 


\section{Processing and elaboration of olives and olive oil}

In this section, the steps required for obtaining high-quality olive oil (extra virgin) and table olives will be described. It is important to know the details of the processing in order to understand in which step can the contamination by herbicides take place.

\subsection{Olive oil}

\subsubsection{Harvest of olives}

The harvest of the olives could be understood as an independent activity from the elaboration of the oil. However, the characteristics of the oil are highly influenced by the harvest time and method employed.

Olives must be picked at the moment of optimum ripeness, where the fruit presents the maximum content of oil and the best characteristics. Olives reach their ripeness in autumn and picking starts at the end of November, lasting up to February or March. The methods to harvest the olives have not changed much from the ancient time. The methods used should not damage the fruit and should avoid breaking of boughs or shoots. The high-quality olive oil is obtained by "milking" the olives into a sack tied around the harvester's waist (using ladders for the highest boughs) and extending canvases at the foot of the trees, where the olives will fall when the tree is beaten (using flexible poles). Recent methods make use of harvester machines (shakers) that generate the vibration on the tree for the falling of the fruit. This vibration machines can be small vibrators operated by the farmer in the required boughs, of full-equipped tractors, with vibration units for the whole trunk of the tree and an umbrella to pick the olives.

Harvest by hand is impossible in olive trees of 4-5 meters high, even with the use of ladders. In general, the trunks are to wide to allow the use of vibration machines and the olives are picked directly from the ground after they fall down when they reach ripeness. Hence, harvest period lasts longer, even until spring when it is a high-production year. When the olives are picked from the ground, weeds have to be completely eliminated from the zone in order to make it easier the picking. The quality of the olive oil obtained from this olives is poor due to organoleptics flaws such as soil flavor.

\subsubsection{Washing}

Traditionally, agricultural workers have cleaned the fruit in the fields by means of sieves. But this cleaning is not complete and the fruit goes into the olive-oil mill with a great quantity of impurities, leaves, branches, mud, etc, which are necessary to eliminate. Therefore, for this purpose, cleaners that use air current or shaking sieves are used to eliminate leaves, branches and other impurities lighter than the fruits. In addition, washing devices are employed to eliminate heavier impurities such as stones or dust. In next figures, both cleaning steps, the one with the air for light impurities (Figure 1) and the other one by washing for heavy impurities (Figure 2), are shown.

Once the fruit has been cleaned and weighed, it is stored in hoppers until it can be crushed. The storage period must be as short as possible in order to avoid alterations, which will produce oils with a higher degree of acidity, lower stability and worse flavor. 


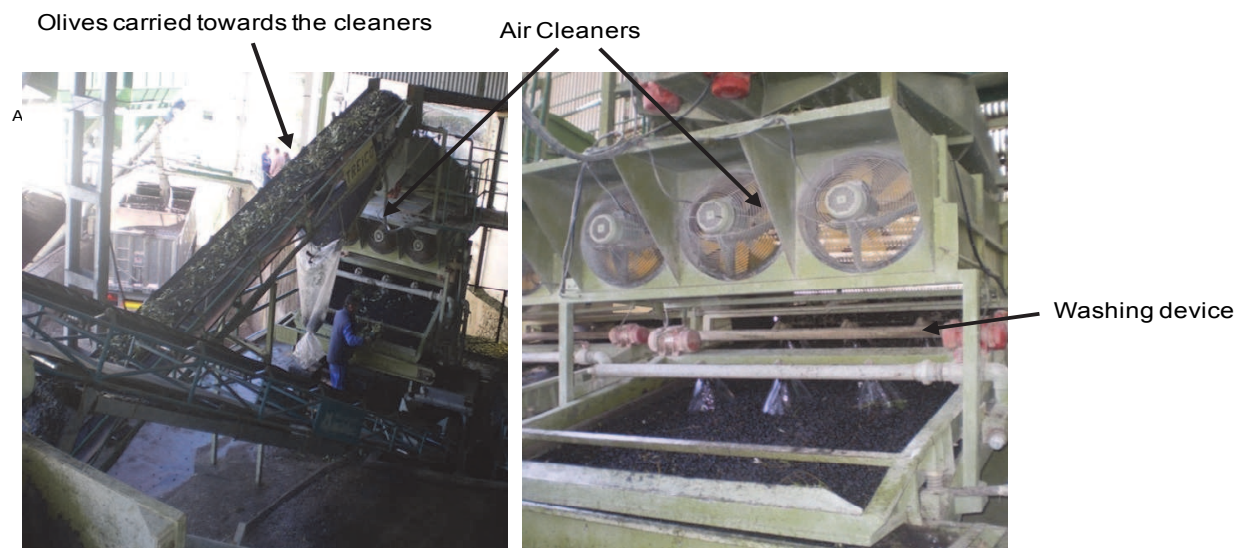

Fig. 1. Cleaning steps for olive fruit.

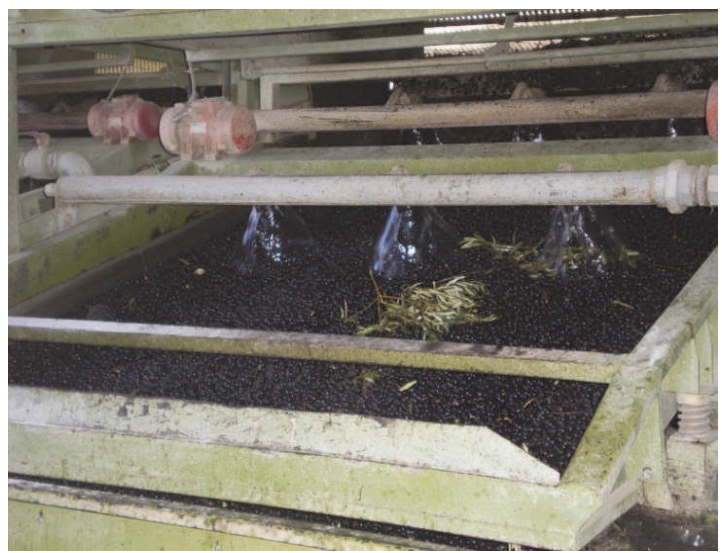

Fig. 2. Washing step for olive fruit.

\subsubsection{Preparation}

The process of releasing the oil from the plant tissue begins by milling the olives to tear the flesh cells in order to let the oil run out of the vacuoles. This is followed by stirring the olive paste to permit the formation of large drops of oil and to break up the oil-water emulsion. In so-called "dual-phase decanters" the oil is then separated by direct continuous centrifugation from the pomace, which consists of vegetable matter and water. The yield of oil varies from 80 to $90 \%$ of the total oil content of the olives, because the oil in the olive paste is only partially free to escape and part of it remains in the unbroken cells or is trapped in the tissues of the cytoplasm, or is emulsified in the aqueous phase.

After the extraction of virgin olive oil from the olives, the remaining paste is called pomace and still contains a small quantity (2-6\%) of oil that can only be extracted with chemical solvents. This is done in specialized chemical plants, not in the oil mills and the obtained oil is called pomace oil. 
The FFA limit in olive oil for direct consumption is $2 \%$. Virgin olive oils with higher content are called "lampantes" and must be refined prior to consumption. The components to be removed are all those ones that are detrimental to the flavor, color and stability of the oil, mainly FFA, phosphoacylglycerols, pigments, volatiles and contaminants. The standard processes used are chemical and physical refining. The main difference between both processes is that chemical refining procedure includes caustic soda treatment to neutralize the oil while, following physical refining, FFA are eliminated by distillation during deodorization. Physical refining reduces the loss of neutral oil, minimizes pollution and enables recovery of high quality FFA. Nevertheless, not all oils can be physically refined.

\subsection{Table olives}

"Table olives" means the product: a) prepared from the sound fruit of varieties of the cultivated olive tree (Olea europaea L.) that are chosen for their production of olives whose volume, shape, flesh-to-stone ratio, fine flesh taste, firmness and ease of detachment from the stone make them particularly suitable for processing; b) treated to remove its bitterness and preserved by natural fermentation or by heat treatment, with or without the addition of preservatives; c) packed with or without covering liquid (International Olive Oil Council, 2004).

Table olives are classified in one of the following types according to the degree of ripeness of the fresh fruits:

- Green olives: Fruits harvested during the ripening period, prior to colouring and when they have reached normal size.

- Olives turning color: Fruits harvested before the stage of complete ripeness is attained, at colour change.

- Black olives: Fruits harvested when fully ripe or slightly before full ripeness is reached.

To prevent olive damage, fruits destined for table olives production are picked by hand and carefully placed in special padded basket that are hung by their neck. Olive transportation is carried out in perforated plastic containers, which have plastic netting as walls (supported by an iron structure). The perforated walls permit the aeration of the fruits and the reduced weight also contributes to minimizing the damage of the fruits. Sometimes, olives are also transported in bulk, although this transportation system is not recommended due to the increased risk of damaging the olives.

Once the olives have been transported, their processing takes place. In general, any processing method aims to remove the natural bitterness of the fruit, caused by the glucoside oleuropein. The bitterness may be removed by alkaline treatment, by immersion in a liquid to dilute the bitter compound, or by biological processes. The product so obtained may be preserved in brine according to its specific characteristics, in dry salt, in a modified atmosphere, by heat treatment, my preservatives, or by acidifying agents. The most common trade preparations are (Sánchez et al., 2006):

- Treated olives: Olives that have undergone alkaline treatment, then packed in brine in which they undergo complete or partial fermentation, and preserved or not by the addition of acidifying agents. The most common preparation is "treated green olives in brine". 
- Natural olives: Olives placed directly in brine in which they undergo complete or partial fermentation, preserved or not by the addition of acidifying agents. The most common preparation is "natural black olives".

- Olives darkened by oxidation: Olives preserved in brine, fermented or not, darkened by oxidation in an alkaline medium and preserved in hermetically sealed containers subjected to heat sterilisation; they shall be a uniform black color. They are also known as "black olives".

Other trade preparations include dehydrated and/or shrivelling olives and specialities prepared in different forms.

\section{Pesticides: definition and classification}

The denomination pesticides (or plaguicides) include a wide variety of products that are very different in their chemical composition and characteristics. A plaguicide can be described as a substance (or formulation containing at least one of them) that presents any of the following uses:

- Fight agents that can be harmful for the crops or prevent the potential effects of these agents.

- Control or regulate the vegetable production.

- Protect the vegetable production, including woods.

- Destruct weeds.

- Destruct part of the vegetables or prevent undesirable growths.

- Destruct or prevent the action of potentially harmful organisms different to the ones that attack plants.

Taking into account the specific action of the plaguicides, different classifications can be made, being the decimal classification one of the most frequently used:

- Insecticides are used against insects and they include ovicides and larvicides (against eggs and larvae of insects, respectively). Nearly all insecticides have the potential to significantly alter ecosystems, being many of them toxic to humans.

- Acaricides kill members of the Acari group, which includes ticks and mites.

- Fungicides are chemical compounds or biological organisms used to kill or inhibit fungi or fungal spores.

- Nematocides, disinfectants and fumigants in general, used to kill parasitic nematodes.

- Herbicides are used to kill unwanted plants while leaving the desired crop relatively unharmed.

- Phytoregulators and similar products can be used to improve the potential of the trees.

- Molusquicides and rodenticides are used to control molluscs (slugs and snails) and rodents pests.

- Post-harvest pesticides and seeds.

- Protectors of woods, fibers and derivatives.

- Other specific plaguicides.

Laboratory studies show that pesticides can cause health problems, such as birth defects, nerve damage, cancer, and other effects that might occur over a long period of time. However, these effects depend on how toxic the pesticide is and how much of it is 
consumed. Some pesticides also pose unique health risks to children. For these reasons, the governments carefully regulate pesticides to ensure that their use does not pose unreasonable risks to human health or the environment.

The mechanisms of action of the plaguicides over the organism are very different depending on the chemical composition. These mechanisms are well-known for some pesticides, even at the molecular level. However, they are completely unknown for some others. Even among pesticides from the same family, some of them can be classified as scarcely toxic while others are very toxic. As a result, it is difficult to establish general rules when dealing with the toxicity of plaguicides.

Herbicides are required to control the growth of weeds. The absence of weeds in the soil around the olive tree presents two major benefits: the weeds do not waste water resources for the olive trees and the harvest of olives from the soil is easier when they naturally fall down from the tree.

Depending on the period of application, herbicides can be classified as:

- Pre-emergents, applied at the starting of autumn.

- $\quad$ Early post-emergents, applied by the middle of autumn, after the early rainings.

- Post-emergents, applied in spring against perennial weeds.

In Table 1, the herbicides that are usually employed in the Spanish olive groves are shown. Simazine, which is forbidden, is also present because it is very persistent and has to be analyzed in order to ensure the absence of residues. The herbicides comprise triazines (simazine, atrazine, trietazine, terbuthylazine and terbutrine), phenylurea diuron and phenylether oxyfluorphen.

The water solubility (W.S.) at $25{ }^{\circ} \mathrm{C}$ and the $\mathrm{K}_{\mathrm{O} / \mathrm{w}}$ value are also presented in Table 1 . The $\mathrm{K}_{\mathrm{O} / \mathrm{W}}$ value is the partition coefficient between octanol and water, and its logarithm is an indication of fat solubility of the pesticide. A high value of the coefficient $\mathrm{K}_{\mathrm{O} / \mathrm{W}}$ for a particular plaguicide indicates that its solubility in water is low; hence, this plaguicide would be fat-soluble and there would be risks of bio-accumulation in fatty tissues. It has been demonstrated that fat-soluble pesticides tend to concentrate in olive oil during its production and extraction from the olives. For this reason, higher concentration levels of fatsoluble plaguicides are expected in the oil than in the olives from which the oil was produced. On the other hand, polar pesticides do not tend to preconcentrate in olive oil and their concentration is lower.

Monitoring herbicide residues in olive oil and table olives is of great interest to ensure food safety related to their use. The development of multi-residue methods is required in this case in order to determine all the herbicides in the same analysis. These methods need to present a high sensitivity in order to be able to analyze the samples at the legislated MRLs.

The analysis of herbicides in these samples is very challenging, because of the inherent complexity of the matrix. As a result, it is necessary to extract the pesticide fraction from the whole matrix to isolate the compounds that will be analyzed. Taking into account that some herbicides are fat-soluble, it is difficult to completely separate them from the matrix. Hence, a clean-up step is required after the extraction procedure. 


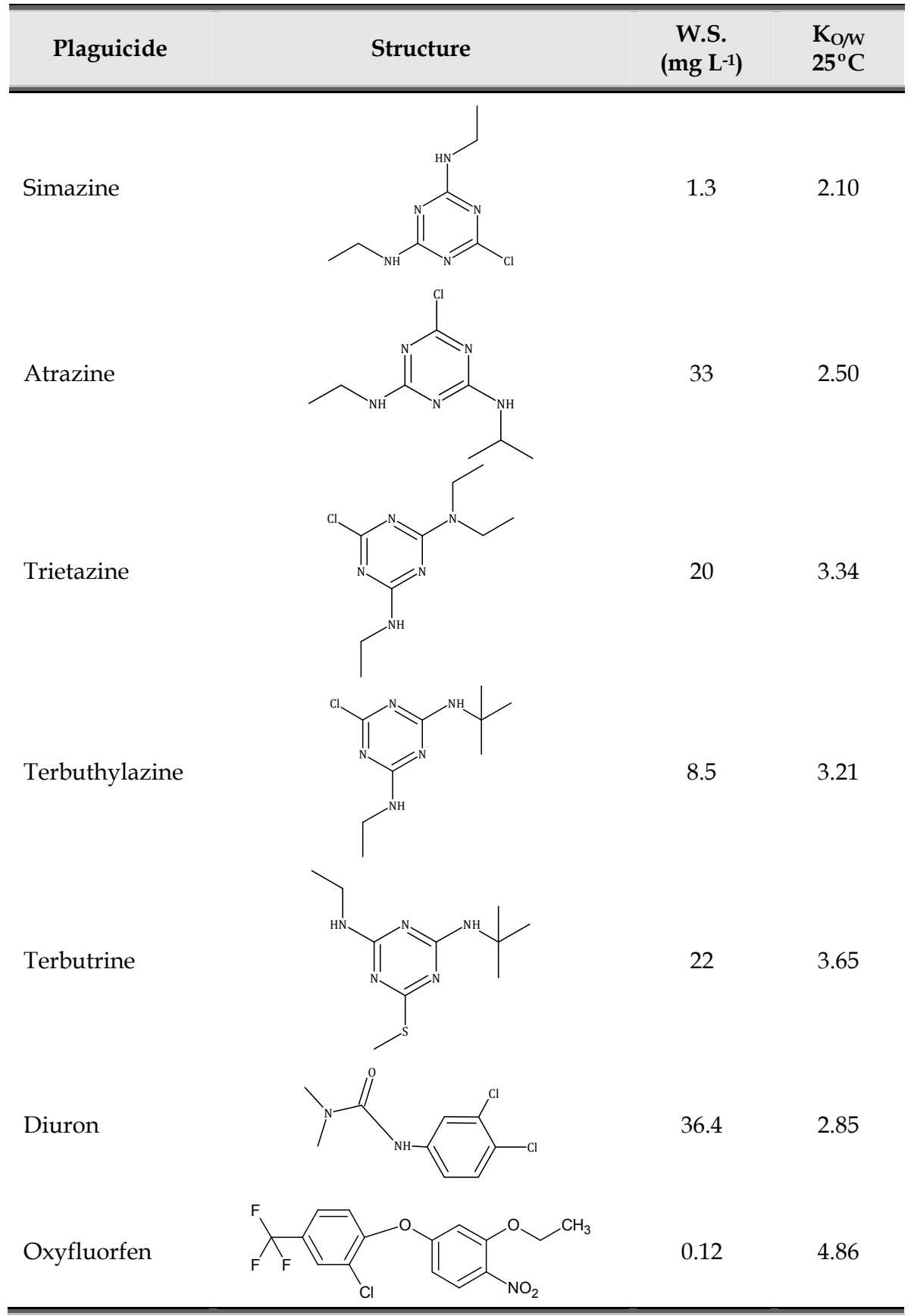

Table 1. Herbicides in olive groves. 


\section{Sample preparation}

The first step required in the analysis of herbicides is to separate the analytes from the matrix and other interfering compounds, therefore isolating the herbicides from the rest of the sample. This separation includes extraction, pre-concentration and clean-up steps, although sometimes they can be performed at the same time (Gilbert-López et al., 2009; Mukherjee \& Gopal, 1996).

This part of the analysis is critical, because the final results will be completely related to the success of the separation process. The sample has to come into contact with an extractant (solid, liquid or supercritical fluid) in optimized conditions in order to weaken the analytematrix interactions and increase the analyte-extractant interactions.

There is a continuous development of sample-treatment procedures for the isolation of herbicides in samples with relatively high fat content, such as olive oil and olives. The preparation of oil samples for their determination by chromatographic techniques requires the removal of the fatty components from the sample. The main problem associated when working with this kind of samples is that dirty extracts may harm the instruments employed. For this reason, proper extraction and clean-up steps are required. In addition, the different nature and physicochemical properties of the classes of herbicides to be analyzed makes it more complex to select the appropriate extraction methodology.

There are numerous extraction and clean-up procedures. However, the most common ones are solid-liquid or liquid-liquid extraction, gel permeation-chromatography (GPC) and solid-phase extraction (SPE) (Gilbert-López et al., 2009; Mukherjee \& Gopal, 1996; Walters, 1990).

\subsection{Solid-liquid extraction}

In this case, the sample comes to contact with an appropriate solvent. After that, different procedures can be applied to homogenize both phases: ultrasonic agitation and microwave extraction.

Ultrasonic agitation: the solvent interacts with the sample simply by a shaking process. Ultrasonic radiation (frequency of $25-40 \mathrm{~Hz}$ ) causes the vibration of the molecules, increasing the collision between them. Hence, the contact between sample and solvent is enhanced. After the analyte is dissolved in the extractant, a filtration step and the evaporation of the solvent are required.

Microwave extraction: samples are enclosed in high quality Teflon vessels together with the solvent and heated to a controlled temperature with microwave power, being the extract filtered when the process finishes. Electromagnetic irradiation is used to heat the solvent that acts as extractant, which is in most cases a mixture between hexane and acetone.

\subsection{Liquid-liquid extraction}

Usually, it has been the chosen method for the extraction, preconcentration and clean-up of liquid samples. It is based on the relative solubility of the analyte in two different immiscible liquids; therefore, it is an extraction of a substance from one liquid phase into another liquid phase. The liquid sample comes to contact with an appropriate solvent (immiscible with the 
sample) and, after a mixing time, both phases (sample and extractant) are separated. During the mixing period, the analyte is distributed between both phases until it reaches the equilibrium.

The $\mathrm{K}_{\mathrm{O} / \mathrm{w}}$ value is critical to decide the appropriate extractant. If this value is high, it indicates that the analyte tends to dissolve in the organic phase instead of in water. As a general rule, the organic solvents selected are volatile substances that present high affinity for the analytes and are immiscible with the sample.

\subsection{Gel-permeation chromatography}

It is probably the most extensively used technique for the analysis of pesticide residues in olive oil, usually after a liquid-liquid extraction. In this technique, an aliquot of an olive oil extract (obtained from the extraction step) is injected into the GPC system. The selected fraction is collected and, after a solvent-exchange step, the sample is analyzed by GC. A GPC system is composed of a chromatographic pump, a fraction collector and a detector. The columns are made from polymeric porous microspheres that enable the separation of compounds according to their molecular weights (which are related to the size of the compound). Using this principle, the herbicide fraction is separated from the triglyceride fraction, which presents higher molecular weight. In GPC, the compounds are eluted from higher to lower molecular weight.

\subsection{Solid-phase extraction}

It is a separation process by which compounds that are dissolved or suspended in a liquid mixture are separated from other compounds in the mixture according to their physical and chemical properties. SPE is used to concentrate and purify samples for analysis and to isolate the analytes of interest from a wide variety of matrices.

SPE uses the affinity of the analytes dissolved or suspended in a liquid (known as the mobile phase) for a solid through which the sample is passed (known as the stationary phase) to separate a mixture into desired and undesired components. The result is that either the desired analytes of interest or undesired impurities in the sample are retained on the stationary phase. The portion that passes through the stationary phase is collected or discarded, depending on whether it contains the desired analytes or undesired impurities. If the portion retained on the stationary phase includes the desired analytes, they can then be removed from the stationary phase for collection in an additional step, in which the stationary phase is rinsed with an appropriate eluent.

The stationary phase comes in the form of a packed syringe-shaped cartridge that can be mounted on its specific type of extraction manifold. The manifold allows multiple samples to be processed by holding several SPE media in place and allowing for an equal number of samples to pass through them simultaneously. A typical cartridge SPE manifold can accommodate up to 24 cartridges and is equipped with a vacuum port. Application of vacuum speeds up the extraction process by pulling the liquid sample through the stationary phase. The analytes are collected in sample tubes inside or below the manifold after they pass through the stationary phase. 
Solid phase extraction cartridges are available with a variety of stationary phases, each of which can separate analytes according to different chemical properties. Most stationary phases are based on silica that has been bonded to a specific functional group.

\section{Detection techniques for the analysis of pesticides. Gas chromatography}

Pesticides (herbicides, fungicides or insecticides) are the most abundant environmental pollutants found in soil, water, atmosphere and agricultural products, and may exist in harmful levels and pose an environmental threat. Even low levels of these contaminants can cause adverse effects on humans, plants, animals and ecosystems. As it has been commented in the Introduction, there are several alternatives for the determination of pesticides in different kinds of samples. In this sense, automated systems of analysis with spectroscopic or electrochemical detection have been developed (Llorent-Martínez et al., 2011). In particular, the development of sensors have been specially useful. Electrochemical sensors present the advantages of miniaturization, simplicity, possibility of in-situ measurements and low-cost. In general, the main contribution of these sensors to pesticide analysis has consisted of the development of methods of analysis for determining a whole family of compounds (Du et al., 2009; Halámek et al., 2005; Liu \& Lin, 2006). In spectroscopic methods, fluorescence (Calatayud et al., 2006; Mbaye et al., 2011) or chemiluminescence (Catalá-Icardo et al., 2011; López-Paz \& Catalá-Icardo, 2011) detections have been usually employed due to their intrinsic sensitivity and selectivity. Among the spectroscopic methods of analysis, the design of flow-through optosensors has also been paid particular attention (Llorent-Martínez et al., 2011). These sensors present enhanced sensitivity and selectivity and have been applied to the determination of a small number of pesticides in different kind of samples (Llorent-Martínez et al., 2005; Llorent-Martínez et al., 2007; López Flores et al., 2007).

In general, electrochemical sensors can provide a useful tool when a whole family of compounds is targeted, while optosensors provide an interesting approach in order to quantify a small number of analytes in a particular sample. However, chromatographic techniques are still the chosen ones when a multi-residue analysis is required, being GC the most common one for the analysis of pesticides.

GC is an analytical technique that is used for separating and analysing compounds that can be vaporized without decomposition (Harris, 2007; Skoog et al., 1996). Typical uses of GC include testing the purity of a particular substance, or separating the different components of a mixture. In GC, the mobile phase is a carrier gas, usually an inert gas such as helium or an unreactive gas such as nitrogen. The stationary phase is a microscopic layer of liquid or polymer on an inert solid support, inside a piece of glass or metal tubing called column. A gas chromatograph uses a flow-through narrow tube known as the column, through which different chemical constituents of a sample pass in a gas stream (carrier gas, mobile phase) at different rates depending on their various chemical and physical properties and their interaction with a specific column filling, called the stationary phase. As the chemicals exit the end of the column, they are detected and electronically identified. The function of the stationary phase in the column is to separate different components, causing each one to exit the column at a different time (retention time). Other parameters that can be used to alter the order or time of retention are the carrier gas flow rate, column length and the temperature. 
In a GC analysis, a known volume of gaseous or liquid sample is injected into the head of the column using a micro syringe. As the carrier gas sweeps the analyte molecules through the column, this motion is inhibited by the adsorption of the analyte molecules either onto the column walls or onto packing materials in the column. The rate at which the molecules progress along the column depends on the strength of adsorption, which in turn depends on the type of molecule and on the stationary phase materials. Since each type of molecule has a different rate of progression, the various components of the analyte mixture are separated as they progress along the column and reach the end of the column at different times. A detector is used to monitor the outlet stream from the column; thus, the time at which each component reaches the outlet and the amount of that component can be determined.

Different detectors can be used in GC. The most common ones until recent years were the flame ionization detector (FID), the thermal conductivity detector (TCD) and the electron capture detector (ECD). However, nowadays most of the developed analytical methods use GC coupled to mass spectrometry (MS) detectors. In the analytical methods that will be described later, only ECD, thermoionic specific detector (TSD) and MS have been used in our research.

ECD is used for detecting electron-absorbing compounds. It uses a radioactive beta particle (electron) emitter. The electrons are formed by collision with a nitrogen molecule because it exhibits low excitation energy. The electron is then attracted to a positively charged anode, generating a steady current. Therefore, there is always a background signal present in the chromatogram. As the sample is carried into the detector by the carrier gas, analyte molecules absorb the electrons and reduce the current between the collector anode and a cathode. The analyte concentration is thus proportional to the degree of electron capture. ECD is particularly sensitive to halogens, organometallic compounds, nitriles, or nitro compounds.

TSD is a very sensitive but specific detector that responds almost exclusively to nitrogen and phosphorous compounds. It contains a rubidium or cesium silicate (glass) bead situated in a heater coil, at little distance from the hydrogen flame. The heated bead emits electrons by thermionic emission. These electrons are collected under a potential of few volts by an appropriately placed anode, and provides a background current. When a solute containing nitrogen or phosphorous is eluted from the column, the partially combusted nitrogen and phosphorous materials are adsorbed on the surface of the bead. The adsorbed material reduces the work function of the surface and, as consequence, the emission of electrons is increased, raising the current collected at the electrode.

Mass spectrometry (MS) is an analytical technique that measures the mass-to-charge ratio of charged particles. It is used for determining masses of particles, for determining the elemental composition of a sample or molecule, and for elucidating the chemical structures of molecules. The MS principle consists of ionizing chemical compounds to generate charged molecules or molecule fragments and measuring their mass-to-charge ratios. In MS detection: 1) the analytes undergo vaporization; 2) they are ionized by one of a variety of methods (e.g., by impacting them with an electron beam), which results in the formation of charged particles (ions); 3) the ions are separated according to their mass-to-charge ratio in an analyzer by electromagnetic fields; 4) the ions are detected, usually by a quantitative method; and 5) the ion signal is processed into mass spectra. 


\section{Analysis of herbicides}

Our research has focused mainly on the determination of herbicides in olives destined for production of olive oil and olive oil. However, at this moment, we are continuing with this research, analyzing herbicide residues in table olives. On average, $5 \mathrm{~kg}$ of olives are required for the production of $1 \mathrm{~L}$ of oil. Taking into account that most pesticides (including herbicides) are lipophilic, a concentration effect could occur when obtaining the olive oil. Thus, MRL for herbicides have been set by the European Union in both olives and olive oil. For this reason, our research group has developed analytical methods that allow the analysis of the selected herbicides in olive oil and olives. In this section we will describe the analytical procedures that have been employed for this purpose as well as the results obtained.

For olive oil samples (Guardia-Rubio et al., 2006b), the preparation procedure included a liquid-liquid extraction followed by GPC clean-up step: 1) Two grams of the olive oil sample were dissolved in n-hexane saturated in acetonitrile. The solution was transferred to a separation funnel where it was extracted three times with acetonitrile saturated in n-hexane. The extracts were combined in a round-bottomed flask and were concentrated to dryness in a rotary evaporator. 2) The residue was dissolved in the GPC mobile phase (ethyl acetatecyclohexane, 1:1 (v:v)) and injected into the GPC column. The collected eluate fraction was transferred to a round-bottomed flask and concentrated to dryness in a rotary evaporator. 3) The residue was redissolved in cyclohexane and analyzed by GC-MS.

For olive samples (Guardia-Rubio et al., 2007c), approximately $130 \mathrm{~g}$ of olives (including the seeds) were first crushed by means of a hammer mill. Afterwards, a $100 \mathrm{~g}$ portion was weighed in a glass tube and $50 \mathrm{~g}$ of anhydrous sodium sulphate were added. The sample was then extracted twice with light petroleum by homogenization with Ultra-Turrax (a high flow mixing tool) and the extracts evaporated using a vacuum rotary evaporator. The solid residue was dissolved in n-hexane saturated in acetonitrile and the same liquid-liquid extraction and GPC clean-up procedure employed for olive oil were performed before the GC-MS analysis.

The following Table shows the retention times $\left(t_{R}\right)$ and analytical parameters obtained for each selected herbicide, including the detection limit (DL). The procedures previously detailed were applied to the determination of the cited herbicides in olives and olive oil samples.

As it was commented in Section 3, there are different olive harvesting methods. Depending on this, the olive fruits can be grouped into three categories: a) fruits picked directly from the tree without any contact with the soil (flight olives); b) fruits picked from the ground (soil olives); and c) fruits that are not separated before the elaboration process (nonseparated olives). The separation of flight and soil olive fruits before olive oil elaboration is critical in order to obtain appropriate results (high-quality virgin olive oil). If both fruits are not separated, the quality of the oil and the percentage of extra virgin olive oil obtained decrease. In addition, the harvesting method may be very important for the presence of herbicide residues in olives, because they remain concentrated in the top 5-15 cm of soil, even after several months since their application. 94 and 33 samples of olives and olive oil, respectively, were analyzed. Diuron and terbuthylazine were found in many of these samples, 79 of olives (specially soil olives) and 31 of olive oil. In four of the soil olives, 
diuron levels were higher than the MRL established by the European Union $(0.2 \mathrm{mg} \mathrm{kg-1})$; however, none of the olive oil samples presented levels higher than the corresponding MRL $\left(0.8 \mathrm{mg} \mathrm{kg}^{-1}\right)$. Terbuthylazine was also quantified in many samples with values over the MRL in some of them, being the established MRLs 0.05 and $0.2 \mathrm{mg} \mathrm{kg}^{-1}$ for olives and olive oil, respectively. Although other herbicides were also detected, in most cases the levels were below the quantification limit of the system. In general, the levels of herbicides found in soil olives have been significantly higher than those ones found in flight olives, which have not been in contact with the soil. These results suggest that herbicide residues are mainly caused by the contamination of the olives when they come to contact with the soil after falling down (Guardia-Rubio et al., 2006b; Guardia-Rubio et al., 2006c).

\begin{tabular}{lccccc}
\hline \multirow{1}{*}{ Herbicide } & $\mathbf{t}_{\mathbf{R}}(\mathbf{m i n})$ & \multicolumn{2}{c}{ Olives } & \multicolumn{2}{c}{ Olive oil } \\
\cline { 3 - 6 } & 11.971 & $0.75-125$ & 0.25 & $3-2000$ & 1 \\
\hline Simazine & 12.095 & $1.25-250$ & 0.50 & $5-1000$ & 2 \\
Atrazine & 12.621 & $2.50-200$ & 1.25 & $10-800$ & 5 \\
Trietazine & 12.666 & $0.25-250$ & 0.12 & $1-1000$ & 0.5 \\
Terbuthylazine & 18.125 & $5.00-250$ & 1.25 & $20-1000$ & 5 \\
Terbutrine & 6.908 & $1.25-250$ & 0.12 & $5-1000$ & 0.5 \\
Diuron & 25.918 & $2.50-250$ & 1.25 & $10-1000$ & 5 \\
\hline Oxyfluorfen & & & & $\begin{array}{c}\text { Linear Range } \\
\left(\mu \mathbf{g ~ k g}^{-1}\right)\end{array}$ & 5 \\
\hline \hline
\end{tabular}

Table 2. Analytical parameters for olives and olive oil determination. 
The fruit goes into the olive-oil mill with a great quantity of impurities, leaves, branches, mud, etc, which are necessary to eliminate. Therefore, for this purpose, cleaners and washing devices are employed to eliminate impurities (Section 3), especially present in soil olives. It would be interesting to evaluate what fraction of the herbicides could be eliminated from the olives after the washing process in the olive mill, previous selection of the herbicides that frequently appear in these samples. The selected plaguicides were diuron and terbuthylazine. Our research group presented the first exhaustive study of the influence of the olives washing in the mills over the concentration of these herbicides (Guardia Rubio et al., 2006a; Guardia Rubio et al., 2007a; Guardia-Rubio et al., 2007b; Guardia-Rubio et al., 2008). Olive samples were collected before and after the washing process in the mill and were analyzed by GC-MS.

The most outstanding conclusion from the obtained results was the drastic reduction in the levels of herbicides in soil olives after the washing process when compared to the same olive samples before the washing step. The washing process significantly diminished the levels of residues of herbicides in soil olives, while the influence of the washing step was not clearly appreciated in flight olives. In the case of non-separated olives, it is interesting to remark that some of the washed olives presented higher levels of herbicides than the non-washed ones. This can be due to the contamination of herbicides-free olives during the washing process. The washing machines for the olives are cleaned and filled with fresh water at the starting of the day. With this water, up to $160000 \mathrm{~kg}$ of olives can be washed before the water is changed next day. The water can be contaminated after the washing of soil olives, therefore contaminating following herbicides-free olives in the washing process. Therefore, the water and mud from the olive washing devices were analyzed to confirm this theory. The procedures employed for both type of analyses follow:

a. In the case of washing water samples, they were first filtered and then slowly passed through a SPE cartridge packed with $\mathrm{C}_{18}$ using a 12-port SPE vacuum manifold. The retained herbicides were then eluted from the solid phase with dichloromethane. The eluate, filtered and dried with anhydrous $\mathrm{Na}_{2} \mathrm{SO}_{4}$, was evaporated to dryness and the residue was dissolved in cyclohexane for GC-MS analysis.

b. In the case of mud samples, a solid-liquid extraction was carried out with a mixture of cyclohexane/acetone (3:1) in an ultrasonic water bath. The extracts were then filtered to eliminate particulate material, dried with anhydrous $\mathrm{Na}_{2} \mathrm{SO}_{4}$ and evaporated to dryness by means of a rotary evaporator. After that, an additional clean-up step was necessary in order to remove any remaining fat in the extract after the extraction procedure. This step involved the use of a chromatographic column that was packed with activated alumina suspended in cyclohexane. Once the extract was applied to the column, a mixture of cyclohexane/acetone (3:1, v:v) followed by dichloromethane was used to elute the herbicides. Once the eluate was evaporated and redissolved in cyclohexane, the sample could be analyzed by GC with ECD or TSD detection.

From the analyses carried out over mud and washing water samples, the following results were obtained: a) regarding water analysis, the waters from an olive mill were collected at different times during the same day, and it was observed that the concentration of herbicides increased continuously along the day. An increase in the amount of washed 
olives meant an increase in herbicide residues. These results confirmed that the waters were being continuously contaminated with herbicides and a decontamination process would be required in the middle of the day (Guardia-Rubio et al., 2008); b) with respect to mud samples, 18 samples were analyzed. Diuron and terbuthylazine were found in nearly all the analyzed samples. Diuron appeared in all samples at concentration levels that ranged between 2.8 and $401.3 \mathrm{ng} \mathrm{g}^{-1}$. Terbuthylazine was detected in 16 samples at concentration levels between 7 and $1031.4 \mathrm{ng} \mathrm{g}^{-1}$. Simazine, prohibited in olive farming in the European Community but a very persistent pollutant, was detected in four samples, although in three of them the concentration was below the quantification limit (Guardia Rubio et al., 2006a). In general, the analysis of mud and waters from the washing device showed that, although the washing process eliminate a high percentage of the herbicide residues, a control over the reused washing water needs to be performed.

\section{Conclusions}

The production of virgin olive oil has increased in recent years and it is being exported to different countries, representing an important part of the economy in some Mediterranean countries. As we described in this chapter, it poses a lot of beneficial properties for the human health. However, it is important to carry out exhaustive quality controls in order to maintain its high standards. One of the most important ones is the analysis of residues of pesticides (including herbicides), which can be very dangerous for the human body, presenting different adverse effects over the organism depending on their toxicity. Here, we have described the methods developed in our research group for the analysis of herbicides in olives and olive oil. It has been shown that diuron and terbuthylazine are commonly found in these samples, although usually at levels below the established MRLs. In addition, the separation of flight and soil olives, together with the washing process in the olive mills, is a critical step to control the levels of herbicides. However, the efficiency of the washing step decreases over the time and the washing waters need to be replaced in order to keep the process being useful along the whole working day. Although the studies here presented have focused on the analysis of olive oil and olives destined to oil production, further research is currently being performed for the analysis of processed table olives.

\section{References}

Calatayud, J.M., De Ascenção, J.G. \& Albert-García, J.R. (2006). FIA-fluorimetric determination of the pesticide 3-indolyl acetic acid. Journal of Fluorescence, Vol. 16, No. 1, (January 2006), pp. 61-67, ISSN: 1053-0509

Catalá-Icardo, M., López-Paz, J.L. \& Peña-Bádena, A. (2011). FI-photoinduced chemiluminescence method for diuron determination in water samples. Analytical Sciences, Vol. 27, No. 3, (March 2011), pp. 291-296, ISSN: 0910-6340

Cicerale, S., Lucas, L. \& Keast, R. (2010). Biological activities of phenolic compounds present in virgin olive oil. International Journal of Molecular Sciences, Vol. 11, No. 2, (February 2010), pp. 458-479, ISSN: 1422-0067 
Du, D., Wang, J., Smith, J.N., Timchalk, C. \& Lin, Y. (2009). Biomonitoring of organophosphorus agent exposure by reactivation of cholinesterase enzyme based on carbon nanotube-enhanced flow-injection amperometric detection. Analytical Chemistry, Vol. 81, No. 22, (October 2009), pp. 9314-9320, ISSN: 00032700

El, S.N. \& Karakaya, S. (2009). Olive tree (Olea europaea) leaves: Potential beneficial effects on human health. Nutrition Reviews, Vol. 67, No. 11, (November 2009), pp. 632-638, ISSN: 0029-6643

Gilbert-López, B., García-Reyes, J.F. \& Molina-Díaz, A. (2009). Sample treatment and determination of pesticide residues in fatty vegetable matrices: A review. Talanta, Vol. 79, No. 2, (July 2009), pp. 109-128, ISSN: 0039-9140

Guardia Rubio, M., Banegas Font, V., Molina Díaz, A. \& Ayora Cañada, M.J. (2006a). Determination of triazine herbicides and diuron in mud from olive washing devices and soils using gas chromatography with selective detectors. Analytical Letters, Vol. 39, No. 4, (March 2006), pp. 835-850, ISSN: 0003-2719

Guardia-Rubio, M., Fernández-de Córdova, M.L., Ayora-Cañada, M.J. \& Ruiz-Medina, A. (2006b). Simplified pesticide multiresidue analysis in virgin olive oil by gas chromatography with thermoionic specific, electron-capture and mass spectrometric detection. Journal of Chromatography A, Vol. 1108, No. 2, (March 2006), pp. 231-239, ISSN: 0021-9673

Guardia-Rubio, M., Ruiz-Medina, A., Molina-Díaz, A. \& Ayora-Cañada, M.J. (2006c). Influence of harvesting method and washing on the presence of pesticide residues in olives and olive oil. Journal of Agricultural and Food Chemistry, Vol. 54, No. 22, (November 2006), pp. 8538-8544, ISSN: 0021-8561

Guardia Rubio, M., Ruiz Medina, A., Pascual Reguera, M.I. \& Fernández de Córdova, M.L. (2007a). Multiresidue analysis of three groups of pesticides in washing waters from olive processing by solid-phase extraction-gas chromatography with electron capture and thermionic specific detection. Microchemical Journal, Vol. 85, No. 2, (April 2007), pp. 257-264, ISSN: 0026-265X

Guardia-Rubio, M., Ayora-Cañada, M.J. \& Ruiz-Medina, A. (2007b). Effect of washing on pesticide residues in olives. Journal of Food Science, Vol. 72, No. 2, (March 2007), pp. C139-C143, ISSN: 1750-3841

Guardia-Rubio, M., Marchal-López, R.M., Ayora-Cañada, M.J. \& Ruiz-Medina, A. (2007c). Determination of pesticides in olives by gas chromatography using different detection systems. Journal of Chromatography A, Vol. 1145, No. 1-2, (March 2007), pp. 195-203, ISSN: 0021-9673

Guardia-Rubio, M., Ruiz-Medina, A., Molina-Díaz, A. \& Ayora-Cañada, M.J. (2008). Pesticide residues in washing water of olive oil mills: Effect on olive washing efficiency and decontamination proposal. Journal of the Science of Food and Agriculture, Vol. 88, No. 14, (November 2008), pp. 2467-2473, ISSN: 00225142

Halámek, J., Pribyl, J., Makower, A., Skládal, P. \& Scheller, F.W. (2005). Sensitive detection of organophosphates in river water by means of a piezoelectric biosensor. Analytical 
and Bioanalytical Chemistry, Vol. 382, No. 8, (August 2005), pp. 1904-1911, ISSN: $1618-2642$

Harris, D.C. (2007) Quantitative Chemical Analysis, Freeman and Company, ISBN: 0716770415, New York

International Olive Oil Council. (2004). Trade Standard applying to table olives. COI/OT/NC No.1

International Olive Council. (2010). Trade Standard Applying to Olive Oils and OlivePomace Oils. COI/T.15/NC.

Liu, G. \& Lin, Y. (2006). Biosensor based on self-assembling acetylcholinesterase on carbon nanotubes for flow injection/amperometric detection of organophosphate pesticides and nerve agents. Analytical Chemistry, Vol. 78, No. 3, (February 2006), pp. 835-843, ISSN: 0003-2700

Llorent-Martínez, E.J., García-Reyes, J.F., Ortega-Barrales, P. \& Molina-Díaz, A. (2005). Flowthrough fluorescence-based optosensor with on-line solid-phase separation for the simultaneous determination of a ternary pesticide mixture. Journal of $A O A C$ International, Vol. 88, No. 3, (May 2005), pp. 860-865, ISSN: 1060-3271

Llorent-Martínez, E.J., García-Reyes, J.F., Ortega-Barrales, P. \& Molina-Díaz, A. (2007). Multicommuted fluorescence based optosensor for the screening of bitertanol residues in banana samples. Food Chemistry, Vol. 102, No. 3, (July 2007), pp. 676-682, ISSN: 0308-8146

Llorent-Martínez, E.J., Ortega-Barrales, P., Fernández-de Córdova, M.L. \& Ruiz-Medina, A. (2011). Trends in flow-based analytical methods applied to pesticide detection: A review. Analytica Chimica Acta, Vol. 684, No. 1-2, (January 2011), pp. 21-30, ISSN: 0003-2670

López Flores, J., Molina Díaz, A. \& Fernández de Córdova, M.L. (2007). Development of a photochemically induced fluorescence-based optosensor for the determination of imidacloprid in peppers and environmental waters. Talanta, Vol. 72, No. 3, (May 2007), pp. 991-997, ISSN: 0039-9140

López-Paz, J.L. \& Catalá-Icardo, M. (2011). Analysis of pesticides by flow injection coupled with chemiluminescent detection: A review. Analytical Letters, Vol. 44, No. 1-3, (January 2011), pp. 146-175, ISSN: 0003-2719

Mbaye, M., Gaye Seye, M.D., Aaron, J.J., Coly, A. \& Tine, A. (2011). Application of flow injection analysis-photo-induced fluorescence (FIA-PIF) for the determination of a-cypermethrin pesticide residues in natural waters. Analytical and Bioanalytical Chemistry, Vol. 400, No., 2, (April 2011), pp. 403-410, ISSN: 16182642

Mukherjee, I. \& Gopal, M. (1996). Chromatographic techniques in the analysis of organochlorine pesticide residues. Journal of Chromatography A, Vol. 754, No., 1-2, (November 1996), pp. 33-42, ISSN: 0021-9673

Sánchez, A.H., García, P. \& Rejano, L. (2006). Trends in table olives production. Grasas y aceites, Vol. 57, No. 1, (January-March 2006), pp. 86-94, ISSN: 00173495

Skoog, D.A.,West, D.M. \& Holler, F.J. (1996) Fundamentals of Analytical Chemistry, Saunders College, ISBN: 0030355230, Philadelphia 
Walters, S.M. (1990). Clean-up techniques for pesticides in fatty foods. Analytica Chimica Acta, Vol. 236, pp. 77-82, ISSN: 0003-2670 


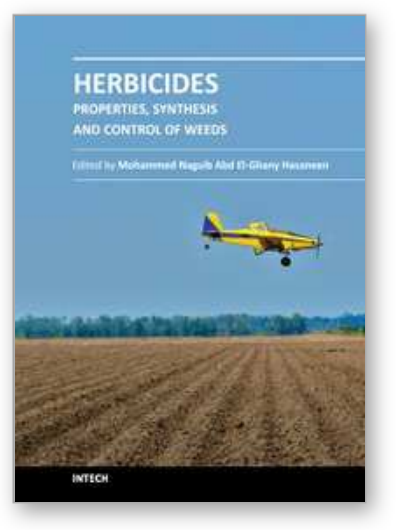

\author{
Herbicides - Properties, Synthesis and Control of Weeds \\ Edited by Dr. Mohammed Nagib Hasaneen
}

ISBN 978-953-307-803-8

Hard cover, 492 pages

Publisher InTech

Published online 13, January, 2012

Published in print edition January, 2012

This book is divided into two sections namely: synthesis and properties of herbicides and herbicidal control of weeds. Chapters 1 to 11 deal with the study of different synthetic pathways of certain herbicides and the physical and chemical properties of other synthesized herbicides. The other 14 chapters (12-25) discussed the different methods by which each herbicide controls specific weed population. The overall purpose of the book, is to show properties and characterization of herbicides, the physical and chemical properties of selected types of herbicides, and the influence of certain herbicides on soil physical and chemical properties on microflora. In addition, an evaluation of the degree of contamination of either soils and/or crops by herbicides is discussed alongside an investigation into the performance and photochemistry of herbicides and the fate of excess herbicides in soils and field crops.

\title{
How to reference
}

In order to correctly reference this scholarly work, feel free to copy and paste the following:

Antonio Ruiz-Medina and Eulogio J. Llorent-Martinez (2012). Evaluation of the Contamination by Herbicides in Olive Groves, Herbicides - Properties, Synthesis and Control of Weeds, Dr. Mohammed Nagib Hasaneen (Ed.), ISBN: 978-953-307-803-8, InTech, Available from: http://www.intechopen.com/books/herbicidesproperties-synthesis-and-control-of-weeds/evaluation-of-the-contamination-by-herbicides-in-olive-groves

\section{INTECH}

open science | open minds

\author{
InTech Europe \\ University Campus STeP Ri \\ Slavka Krautzeka 83/A \\ 51000 Rijeka, Croatia \\ Phone: +385 (51) 770447 \\ Fax: +385 (51) 686166 \\ www.intechopen.com
}

\author{
InTech China \\ Unit 405, Office Block, Hotel Equatorial Shanghai \\ No.65, Yan An Road (West), Shanghai, 200040, China \\ 中国上海市延安西路65号上海国际贵都大饭店办公楼 405 单元 \\ Phone: +86-21-62489820 \\ Fax: $+86-21-62489821$
}


(C) 2012 The Author(s). Licensee IntechOpen. This is an open access article distributed under the terms of the Creative Commons Attribution 3.0 License, which permits unrestricted use, distribution, and reproduction in any medium, provided the original work is properly cited. 